\title{
Formulating Black Womanhood: A Study on Beyoncé's Hip-Hop Song Lyrics in Beyoncé Platinum Edition Album
}

\author{
Ika Ayu Larasati \\ ika.ayularasati@yahoo.com
}

\begin{abstract}
This article aims at understanding the Black womanhood concept through Hip-Hop song lyrics, since song lyrics are not only a part of art but also a media to express people's feelings, education, therapy and entertainment. This article also helps the readers to understand that sexuality portrayed in Hip-Hop song lyrics stands for something and has a function because music is related to the social background, message, function, and effect generated from the artwork.

The qualitative method and interdisciplinary approach are used in conducting this article, which involves the literature, history, culture, sociology, and to enhance the understanding of multi-ethnic America, especially about Black womanhood. The article starts with introduction, a discussion about African American culture in general. To produce an up to date writing, the article choses the recent popular singer, Beyonce. In finding Black womanhood concepts in Beyonce's lyrics. One thing that also needs to be highlighted is Black women's sexuality.

The findings are about Black womanhood from Beyonce's standpoint, such as the Black woman's self-definition, the sisterhood, the relationship between mother and daughter, and the relationship with Black men. In addition, since it highlights the Black woman's sexuality in Hip-Hop that is based on Beyonce's songs, it indicates that recently Black women began to realize that they have power over their own body.
\end{abstract}

Keywords: Black womanhood, sexuality, Hip-Hop music, Lyrics

\section{Introduction}

Hip-Hop emerged in the 1970s when the term Black was booming and it is one of the ways to demonstrate the existence of African Americans. The term Black is also connected with the study of Womanhood, which is an effort of African American women to define their identity, quality, and their distinctiveness in America. The first music that emerged among the slaves that was acceptable and encouraged by slave owners was the spiritual song (Gospel song), for Whites, they who were converting to Christianity and singing the praises of their religion-represented submission to European ideology.

The Black musical style is a combination of elements from African and European tradition; since Americans were Europeans who brought about their cultural heritage, including music. After Gospel, Blues was sung by individuals, who accompanied their own voices with guitar-Love, sex, betrayal, poverty, drinking, bad luck, and an itinerant lifestyle were its themes. Afterwards, it expanded to another popular genre, jazz, with its swing danceable beat. Through the late 1960s and 1970s, there was a Soul and 
soon it moved to songs of political awareness and protest. Along with the Aesthetics Movement, the Black Arts Movement by Amiri Baraka was the period of artistic and literary development among Black Americans culture and life in the 1960s and early 1970s. The Black Arts Movement was a medium to facilitate Blacks' ideals, solidarity, and creativity. This movement contributed to the multiculturalism movement that persuaded people, especially minorities to show their voice, background, and history.

In the $70 \mathrm{~s}$ and ' $80 \mathrm{~s}$, Hip-Hop came out of a dance party and club milieu overseen by a DJ, or Disc Jockey, who spun records. The $\mathrm{MC}$, or Master of Ceremonies, was the key figure in early Rap, a rapid music of rhymed phrases. Rap came out of "African derived oral traditions of storytelling, 'boasting' (self-aggrandizement), 'toasting' (long narrative poems) and 'playing the dozens' (competition of verbal insults)" (Norfleet, 2006, p. 353). Over the past three decades, Rap has been a part of popular culture, an important source of ideas has shaped people's perceptions of themselves and other people; and it has had and continues to have great influence on adolescents as they employ it for self-identity formation (Collins, 2006, p. 39). Rap has functioned as an immensely profitable component of the popular culture apparatus and as an attempt to block progress toward gender equality.

In African American society, Black men and women both have different levels of oppression. Technically, Black men experience racial and economic oppressions. From this, Black men have the possibility to show their power over Black women, the only group left in society that experiences many inequalities. While, being both Black and a woman presents particular difficulties to must be faced social, economical, political and cultural situation. Black women belong to the minority group that is oppressed by White men, White women and also Black men. As stated by Ward and Herndl (1997) stated, "these women are 'doubly marginalized'-they are victims of sexism, racism and classism (p. 34). Alongside of this problem, Black women voiced their situation through many ways; one of them is through Rap.

Lately, Hip-Hop has become more and more explicit and vulgar, hence the double standard of lyrics cannot be avoided. Double standard here means different sets of principles for similar situations, it could be a word, phrase, social norm, or rule. Double standard can be explained as a biased of treatment; for example, in Hip-Hop music, there are male rappers degrade women for their sexuality while society seems to ignore it-in reverse, when female singers expose their body, wear seductive clothes and use harsh words, it creates a polemic. The impact of the emergence of this issue is the negative label received by the female singer, but since there are a lot of Black women in Hip-Hop. This image continues to accumulate and affects the public's opinion toward Black women in general.

It is important to note that within the HipHop music universe, women have never taken their abuse lightly. This case is one of the reasons why Black women need to define their own womanhood, once in the slavery 
era. Black women had been exploited by Whites and this situation caused the controlling images toward them. From this, it can be seen that shaping Black Womanhood cannot be separated from the sociocultural and historical factors, and it is depicted in Hip-Hop lyrics.

Lyrics are frequently connoted with poetry, and always relate to the category of poetic literature that is distinguished from narrative and dramatic tale; they are most representative in their sound patterns and are generally characterized by subjectivity and sensuality of expression (Grolier, 778). Therefore, lyric as literature has an important role in society. Through lyrics, Black womanhood and Black women's sexuality is delivered. On November $24^{\text {th, }} 2014$, Beyoncé launched her new album entitled Beyoncé Platinum Edition, and it was huge. Beyoncé is a prominent figure in $\mathrm{R}$ and $\mathrm{B}$. In addition, she has sold 800,000 copies of her new album in the first three days even without teaser and promotion, and, in this album, she presents many shades of Black Women's experiences from her personal standpoint. That is why her latest album has been selected to be the material object of the study.

\section{Methodology}

This study is a library research and it uses qualitative method to find the concept of Black womanhood and Black women's sexuality in Hip-Hop lyrics. It is an appropriate method since the qualitative method is a form of thick description and explanation in investigating the meaning of the lyrics. In addition, Denzin and Lincoln (2005) confirmed that,

A qualitative research is an activity that consists of a set of interpretive materials that makes the world visible by series of representations, including field notes, interviews, conversations, photographs, recordings, and memos to the self; to interpret phenomena in terms of the meanings people bring to them. ( $p$. $3)$.

Whereas, library research here is a research that is based on any literature from the library or internet as well; collecting and documenting information from textbooks (journals, articles, magazines, newspapers, lyrics).

Furthermore, Creswell (2009) cited some characteristics of qualitative method, "specifically qualitative research is descriptive that the gathered data encompasses transcript, interview, photograph, field notes, video and other notes" (p. 37). This research tends to analyze data inductively - it enables researcher to identify key themes in the area of interest by reducing the material to a set of themes and categories. To conduct the research, there are three steps taken, namely:

a. Collecting data, in this research, the data used are documents such as lyrics, journals, articles, script of interviews, books, and visual materials such as photographs and captures from video to support the analysis. Thus, data were taken from Beyoncé's newest album entitled Beyoncé Platinum Edition album that released at $24^{\text {th }}$ November 2014. 
b. The second step is categorizing data. Here, open coding is needed to uncover and develop concept through the text and expose the thoughts, ideas, and meanings contained therein (Strauss and Corbin, 1998, p. 102) corresponds to the concept of Black womanhood.

c. The third step is analyzing data. First, those data will be analyzed using semiotic theory by Barthes; by using a sign system to find the connotative and denotative meaning conveyed in Beyoncé's song-afterwards, it is necessary to understand the sociocultural background of Blacks American especially about Hip-Hop and also Black womanhood. In this step, the first research problem will be answered, the formula of Black womanhood found in Beyoncé's songs. For the next steps, it focuses on the Black woman sexuality expressed in the lyrics. It requires the captures of Beyoncé's video clip to support the analysis as well as any additional information from other sources.

\section{Findings}

In discussing the view of womanhood, it refers to beliefs, notions, and ideas about women in terms of what they represent in their relationship to society. Typically, people tend to give an expectation about appropriate female roles that culturally constructed.

As mentioned before in the earlier chapter that Black women had a hard time since the beginning of their arrival as slaves, and it affirms by Hooks (1992) said that Black women were taught to override their womanhood since the racist and sexist society had conditioned them to devalue their femaleness, “... we were asked to deny a part of ourselves - and we did" (p. 1). Thus, it arouses some controlling images toward Black women that were the reversed idea of White Womanhood such as mammy, jezebel, matriarch, sapphire, etc.

\section{Black Woman and the Importance of Being Herself}

Women certainly associated with beauty. Beauty is considered very important since pretty face and nice body support their appearance. If a woman has such qualities, it shows that the person is good at taking care of herself. Unfortunately, because of this view point, many women feel insecure and inadequate, as these beauty images make them trying to meet the unreachable beauty standards.

The United States is inhabited by people of various races and ethnic groups, one of which is the Black women. Black women are considered an inferior group and alienated because of their race and gender. The view that Black women are inferior often lowers their self-esteem.

Since the time of slavery, Black women image has been devalued by their White masters, which then gradually constructed Black women perspective to believe that they are imperfect and unacceptable the way they are. That statement is also in line with Taylor (1999) that "the White as the dominant culture has racialised beauty; a beautiful woman according to the Whites is a woman who has features such as fair skin, thin body, 
light eye color, straight and light-colored hair, small nose, and slight bone structure" (p. 17). These standards are certainly contradictive to the Black women's body type which is characterized by dark skin, broad noses, full lips, and kinky hair. This is has affected Black women body satisfaction.

Despite it is no longer the days of slavery, the construction of White beauty is still strongly reflected in media and social interactions such as in magazines, television, movies, and advertisements. Nowadays, White beauty is still an issue for Black women and it is internalized in everyday life. One example of that matter is the depiction of beauty in a song entitled Pretty Hurts (2013). In this song, Beyonce shows that having a good look is a must in society, "Mama said, "You're a pretty girl/ What's in your head, it doesn't matter/ Brush your hair, fix your teeth/ What you wear is all that matters" (Beyonce, 2013, line 6-9). White beauty traits, as mentioned y Paul V. Taylor's writing in the previous paragraph is certainly contrary to Black women's body features such as dark skin, broad noses, full lips, and kinky hair (as cited in Collin, 2006, p. 89). In this song Beyonce described her efforts to achieve White beauty standard by straighten her hair which was originally curly, then to get a perfect smile, Beyonce also had to have the dentist fix her teeth. The lyrics described that a mother would always remind her daughter to always look pretty and attractive, no matter if the girl was intelligent or talented. Beyonce, in one of her interview videos entitled "Self-Titled 2- Imperfection" about her newest album, tells how she spent her childhood struggling, to practice singing, and dancing, and also participating beauty contests. Although she was fairly successful, now she often feels tired, remember that she spent her childhood like that.

"I have this image of trophies, me accepting the awards, kinda a training myself to be this champion. And at the end of the day when you go through all of the things, is it worth it? When you get the trophy and you like... I basically starved, I have neglected all of the people that I love, I confront to what everybody else thinks I should be, and I got the trophy. What is that mean?" (02:37 03:02)

In the video clip of Pretty Hurt, Beyonce appears as a Black woman who a joins beauty pageant. Here, a beauty pageant is a symbol of a place where people can judge a woman by several standards. During the quarantine, all contestants force themselves to maintain perfect appearance. The contestants compete with one another to be the most attractive woman, the way the contestants maintain their body is not by exercising only, but also through strict dieting, cosmetic surgery, and consuming pills. In fact, according to Greer (1999),

every tribe in the world has a different beauty standard, for example, the Karenni women from Burma who wear layers of neck rings which permanently elongate their necks, and also in the Mursi tribe in Africa, there is a practice of lip stretching for women because the bigger the lip, the more desirable the woman becomes and the more eligible she becomes for marriage. (p. 56) 
Hence, the contestants' desire to win this contest shows that there is a generalization in beauty standards, which means women 'must' change their appearance.

The White version of beauty is deeply embedded in society. Beyonce in this case shows the fact that in beauty pageants, she got same expectations about beauty standards, "Blonder hair, flat chest/ TV says, "Bigger is better."/ South beach, sugar free/ Vogue says, "Thinner is better." (Pretty Hurt, 2013, line 18-21). In fact, for Black women it is hard to define their beauty if the standard of society is based on White people's perspective. In line $18-21$, the value of 'pretty', which means to have blonde hair, thin body but large in certain body parts is often the demands of Television and also Vogue. Television and Vogue magazine are the forms of media that have very important roles in defining prettiness. In general, women's magazines are intended for all people but when they are viewed closely, magazines do not accommodate darker women enough. On the front covers of many popular fashion magazines, Black models are rarely used; except like Essence magazine that is intended for Black Women. For Vogue magazine itself, which already appeared in the $19^{\text {th }}$ century, the first Black cover girl was Beverly Johnson in $1974^{1}$. Beside the cover magazine, to the beauty pages, the majority of the beauty tips given are also for people with lighter skin and long straight hair.

Then, besides the magazines, in the lyrics above (Pretty Hurt, 2013, line. 18-21), there is a "Television" which also plays an important role in broadcasting a wide range

1 Retrieved from http://www.bbc.com of beauty information. Sadly, different forms of mass media have different standards of beauty, for instance "TV says bigger is better, but Vogue says thinner is better". As mentioned before that a woman who has light skinned, long hair and a skinny body is considered to be a beautiful woman, but according to Sewel (2013), "with the number of mixed race then, women who have curvaceous body (big breast, narrow waist, and big buttock) is also considered as an attractive woman" (p. 58). Thus, because of the unlimited standards of beauty, women might just decide to take diet pills or get liposuction, wear a lighter shade of foundation or even bleach their skin.

From Pretty Hurt, it shows that self acceptance is very important for Black women, considering that beauty standard in society are impossible. When Black women realize that they are beautiful in their own way, this is the time for Black women to find their self-definition. Actually, the idea of Blacks natural beauty had been proclaimed by Black activists in 1969 as the part of civil rights movement. Black women should be just the way they are in finding beauty, their own identity, without worrying certain standards that make them uncomfortable. Just because a woman is black, according to the present writer's opinion, it does not mean that she cannot wear nice clothes and makeup, she can-as long as she does that for herself, for her happiness. In the end of the Pretty Hurts, Beyonce wrote, "When you're alone all by yourself (pretty hurts, pretty hurts)/ And you're lying in your bed (pretty hurts, pretty hurts)/ Reflection stares right into you (pretty hurts, pretty hurts)/ Are you happy with yourself" (Pretty Hurt, 2013, line 
42-45). Hence, the Black woman's struggle of being pretty is not because of the pressure by some beauty standards in society, but to make the Black woman herself look good, boost her self esteem and feel confident. Just like in her song ***Flawless, Beyonce shows that being a flawless person is possible for anyone at anytime. This song empowers women to be better people started from the simplest things, as the lyrics below stated:

You wake up, flawless

Post up, flawless

Ridin' round in it, flawless

Flossin' on that, flawless

This diamond, flawless

My diamond, flawless

I woke up like this, flawless

(***Flawless, 2013, line 53-66)

There is no need to worry about other people's opinions. If there are bad images of Black women such as the controlling images, then Black women themselves are the ones who must change it, Black women must be tired of being defined by others. It was affirmed by Collin (1991) that, "most Black women are disagree to define themselves as mammies, matriarchs, welfare mothers, mules, or sexually denigrated women" ( $p$. 99), hence, these songs help Black women to rethinking the hegemonic objectification to them as the minority in the society by accepting their situation but did not remain silent and follow the controlling images.

\section{Sisterhood in Beyonce's songs}

Black women experience oppressions in various areas, such as in employment, education, public facilities, and politics.
Unfortunately, these oppressions are performed by Whites, as well as the Black man. Thus, for a Black woman, the only place to survive is within the scope of Black women themselves. Black women build relationships with one another as an effort to reconstruct other party's views and perspectives toward them. Sisterhood here is a bond among women that is not always related by blood, but the solidarity that based on shared experiences or concerns. As Michie (1992) explored that, "the term 'sister' shows the complex quality of women's relationships to one another (siblings or companion), which basically the ideal of sisterhood suggests a close-knit bond between women united against patriarchy and provides a safe space for them" (p. 7). Thus, such friendship helps women to fight against patriarchy perspective, such friendship as a shelter, and a place to 'heal' them. In the process, Black women learn to love, support, and understand other Black women so that they can live and work in solidarity.

Black women have realized that they must unite in harmony to achieve their dream to have equality in society. Even though their lived experiences are unique and individual, there are commonalities among their experiences of living in America. They share a history and a culture. Thus, if one problem is seen with many different perspectives of Black women, then the benefit is not just for one person only but for all Black women. In Beyonce's song entitled Flawless, there is a line "my sister told me I should speak my mind" (***Flawless, 2013, line 73) Although the line is quite short but it clearly shows that the role of a sister is very 
important for Black women. In this section, Beyonce is talking about her sibling, Solange, who inspired her as a Black women to speak her truth. Although Solange is Beyonce's younger sister, she has an important role in Beyonce's survival as a Black woman by giving emotional support and friendship.

From this, it can be seen that childhood, past experiences helped to shape a Black woman and make her into who she is now. The bad experiences in her childhood could not preclude Beyonce to strive to become a successful singer. Being an honest Black woman who shares her experience and opinion is one of the benefits of sisterhood. Sisterhood is useful for a Black woman when it feels like the world is against her. True sisterhood loves, teaches, and encourages its members to strive for the best with a connection to self-balance; a spiritual connection to the past, present, and future (William, 2015, p. 1).

The past shaped Black women today and what happens today affects Black women in the future. Hence, it is important to see the development of Beyonce as a Black woman in sharing her experiences with other Black women. In sisterhood, learning about another Black woman's life can be comforting, supporting and even freeing for other Black women.

\section{Mother-Daughter Relationship in Beyonce's songs}

The mother-child relationship is one of the most vital of all human relationships. A mother has the ability to give birth to continuously regenerate the world. The relationship between a mother and her children is very important, since a mother has social and emotional attachments to her children as a form of bonding, affection, and protection; such a relationship shapes children's patterns of attitudes and behaviors in the future. For daughters, mothers serve as their first teachers and friends who provide vital sources of material and emotional support. To strengthen their relationship, communication is vital to them, as Penington (2004) stated that, "when parents demonstrate a willingness to listen to their child, the child in turn, may demonstrate a willingness to listen in other interpersonal situations" (p. 17). A mother is not the only person whose role is to advise her daughter, but on the one hand, a daughter can give her opinion to resolve problems that occur in a family.

This situation is seen in Beyonce's song entitled Ring Off, basically it focuses on Beyonce's parents' relationship. In this song, there is a 'dialogue' between a daughter and a mother about the process of healing from a failed relationship,

Mama, I understand your many sleepless nights,

When you sit and you think about father,

Or how you tried to be the perfect wife

You used to dress and fix your hair Then you smiled through your tears" (Ring Off, 2014, line 1-5)

From that lyric, there is a connection between Beyonce and her mother, Tina Knowles. It figures her out that Tina has qualities as a Black Superwoman; that she 
has her own hair salon and business, she takes care of her children, she maintains her appearance, and she tries to be a perfect wife, even if trying to be a perfect wife led her to many sleepless nights. Beyonce's father, Mathew Knowles had some public affairs and faced multiple paternity claims. Tina Knowles tried to smile behind her tears. This is similar to the image of a superwoman who is "not allowed" to show her grief, fear, and weakness.

However, Beyonce as a daughter is aware and she understands her mother's situation. Here, just like what Pluhar and Kuriloff (2004) found, "a communication increases trust in the mother-daughter relationship" ( $p$. 310 ), we see that communication in such relationship plays an important role. Communication expresses the importance of listening and supporting in a daughtermother relationship, so that they can make a solid bond between them.

There are some behaviors to respond to the divorce situation, and it is depends on the individual's perspective, on his or her own lifestyle; but according to Livingstone (2012), "behaviors such as denial, bargaining, anger, depression and acceptance" (p. 5) are the most common phases that are experienced by a person during the post-divorce period. In the beginning of the song, there is a situation on how unready Tina was about the divorce,

In the mirror you would stare And say a prayer Like, "I wish he said I'm beautiful I wish it didn't hurt at all I don't know how I got here
I was once the one who had his heart (Ring Off, 2014, line 6-11)

The prayer of Beyonce's mother is a reflection that she was under pressure in the relationship due to Beyonce's father's affairs. Afterwards, the content of Tina's prayer is "I wish... I wish...I don't... I was..", she uses a lot of 'I' as the first person point of view, that it shows how she tried very hard to be a perfect woman, perfect wife, but then the result is not what she expected and it makes her suffered in her marriage. Actually, after Mathew's affair, he and Tina decided to divorce at 2009. This fact is supported by her speech about Tina's personal story in the International Women \& Money Leadership in Houston that was held on October 2014, she said:

"One day my world just exploded and I knew that I had to get a divorce. And at 58 years old, that's a very hard difficult thing. It does something to your whole self-esteem and psyche, because I had been married for 33 years. I have nothing else, it was almost impossible to untangle everything. I knew that I didn't have a choice but to do that. It was a very hard time. I was very sad". (Tina, 2014, 17: 59 - 18: 49)

After the post-divorce depression, poor health, loneliness, and even work inefficiency, the resolving grief is an important part of the process. Working through the stages of grief will affect the person's lifestyle and also the entire family.

Thus, Tina believed that it was never too late to be happy (again), and as a mother, her courage of going through this situation cannot be separated from her daughters' role 
of help and support. Meanwhile, Beyonce as a daughter supported her mother, even when her mother decided to take some 'vacation' to find her passion and purpose in life (after the divorce), and also supported Tina in the decision to get married again.

Based on the song and the real experience of Beyonce's mother, breaking up or divorce is not the end of the world; in fact, it is the time for all women to choose their next move by themselves. It is possible that both sides have different perceptions about something, and then it is important for a mother and a daughter to share their thoughts; from that, both parts will learn something reciprocally.

Thus, a relationship with a mother helps a daughter to develop a sense of self awareness, pride, and identity. Beyond that, for Black women, mother-daughter relationships help them to see, shape, and undergo their womanhood.

\section{Love Relationship in Beyonce's songs}

In America, Black men's and Black women's problems in relationship are more highlighted than the counterpart, the relationships between White Men and White women. This statement is in vein with Muhammad's statistic on marriage in the United States (2011) that focused on Blacks, Latinos, and Whites. It said that, since 1960 until 2007, there is a declined as much as $22 \%$ in the numbers of Whites marriages, while the Latinos' has decline number around $30 \%$, whereas Blacks marriages' decline is amount $34 \%$. Such decline in Blacks marriages, as stated on the article is due to two things, one, there are many unwed professional Black women and second, a lot of imprisoned Black men that time ${ }^{2}$.

This situation is also related to the historical background in America, because the slavery era affected the role of each gender. Young Black boys were taught to be as tough as possible; they had to stand on their own feet to strive toward their rights and life. While for young girls, besides having to work as hard as the Black boys, they were also encouraged to rely on their own achievement, and Black girls had to be resilient to face various oppressions.

Then, Black love or romantic relationship means a relation between a Black man and a Black woman that is more than a physical intimacy, but also compassion, love, and responsibility. The relationship between a Black man and a Black woman is important because it is closely related to their status toward their Black friends, family, community, and also their past. Here, the central discussion is about a Black man and a Black woman since this relationship heals and helps the whole group to become a stronger community.

Black man and Black woman stereotypes play important role in Blacks romantic relationships. This statement is supported by

\section{Muhammad, Starla. Broken Black \\ Relationship: where is the love? Retrieved from \\ http://newamericamedia.org/2011/09/broken- black-relationships-where-is-the-love.php on June 3th, 2015, 6: 39}


Dickson (1993) that, “...we cannot ignore the impact of socialization within the Black family, stereotypes about Black men and women that are perpetuated within the Black community..." (p. 480). Blacks stereotypes or controlling images are received from the dominant society, and it does not mean that the minority should take all of the opinions without any attempt to counter it. Minority groups have significant role in defining themselves in society. As said by Pinderhughes (2002), "Black men play a powerful role in maintaining their status in the social system, and therefore play a part in the problem between men and women" (p. 274). Even in society there are a lot of bad images of Black men, like a notion that black men cannot hold onto a relationship, Black women address such problems not by attacking the Black men but embracing them (Collin, 1991, p. 11). Beyonce has many songs about love relationship that are made to inspire Blacks to build a good relationship out of the stereotypical bad Black relationships. For example in a song entitled Superpower, it can be seen that when a Black woman loves Black man, then the man should treat the woman fairly to build a positive relationship,

When the palm of my two hands, hold each other

That feels different

From when your hands are in mine That's just the way it is, hmmm

And when I'm standing in this mirror, after all these years What I'm viewing is a little different From what your eyes show ya I guess I didn't see myself before ya, moving forward
(Superpower, 2014, line 1-14)

Those lyrics show the state of a person who feels the differences between being single or in a relationship. Beyonce here as a Black woman points out that her partner helped her to see and to solve some particular problems in life, while the line, "I guess I didn't see myself before ya" indicates that the narrator finally finds herself along with her partner's guidance. By staying in a relationship, she feels stronger and believes in herself again after some pressures that happened in her past time and is ready to move forward.

In fact, to support this notion, it is important for Black men and Black women to help each other, Beyonce and her husband Jay-Z, a Black rapper, are considered a power couple due to their success in the American entertainment industry. This predicate could not be separated from the fact that as a couple they are known as a very solid couple that supports one another. Besides their awards and money, their strong bond as a family plays an important role in gaining people's (especially Blacks') attention.

A relationship requires hard work, and Beyonce shows that no relationship is perfect. In the same song, it is also shown that even Beyonce and Jay $\mathrm{Z}$ have particular fears that could affect their relationship. Each individual's past time could affect the current situation. Jay $\mathrm{Z}$ for example, when he was a kid, felt the absence of a father, this is revealed in one of his songs, "Father never taught me how to be a father" (Jay Z, Blue, 2013, 40). His fear of fatherhood was even bigger when he realized that he was going to be a father too. Whereas Beyonce has a fear 
about divorce; it is associated with Tina Knowles failed relationship with Mathew Knowles after thirty years of marriage. Beyonce's fear of divorce is explained by Wanzo (2011) that, "Blacks, especially Black women usually have poor relationships with their fathers and unconsciously it leads these women to choose their partner recklessly" ( $p$. 8). But, in this case, both Beyonce and Jay $Z$ are still working on their relationship until now.

In the real life, Beyonce and Jay $\mathrm{Z}$ are frequently called a power couple because both are equally successful people in music industry. Jay $\mathrm{Z}$ is an undisputed king of rap world with a net worth of $\$ 500$ million in 2013 with 6 Grammys. According to CelebrityNetWorth.com, while Beyonce in same year, she had a net worth of $\$ 350$ million with seven Grammys. From this it can be seen that Beyonce as a Black woman is a very successful person and certainly able to finance her own needs; and also her daughter's needs. Hooks (1992) once said that, "...if a woman has access to economic self-sufficiency, she is more likely to leave a relationship where male domination is the norm; she chooses liberation. She leaves because she can" (p. 49). But so far, even Beyonce is successful financially; it does not make her leaves Jay Z. It shows that a better Black relationship is also supported by a better partner. Jay $\mathrm{Z}$ may be more successful than Beyonce, and the fact that he is the King of Rap and also had a difficult past time, he probably has a tough side to him. In this case, Beyonce's success does not threaten her husband's ego, instead, they are working together to build a strong household.
So far, Beyonce and Jay Z's relationship is very significant, especially for Black women because the couple could counter the stereotypes that exist in society. It shows that it takes mutual care and support from both sides that help Blacks to improve the quality of the individuals and then in turn they can work on the relationship properly.

\section{Women's Sexual Subjectivity in Beyonce's Songs}

To reveal the importance of women's role in hip-hop and in the community, it is necessary to review Black's history in America. Since slavery, images of Black women's deviant sexuality have been used to justify their sexual exploitation; from asexual mammy to hypersexual jezebel. As written by Marshall (1996), that "Black [woman] sexuality was associated with earthiness, impurity, indecency and corruption and as such represented the antithesis of the ideal of English sexual mores" (p. 8). In response to this portrayal, Black women have been silent for a long time and this is due to the lack of access to speak in social institutions.

Conrad et al. (2009) discovered, "Black female characters often were in positions of submission when compared to male characters" (p. 140). This finding was also supported by the fact that in some hip-hop videos, Black women are portrayed as sex objects by the use of revealing clothing. Moreover, the female models in such videos are valued for their ability to use their bodies to be sexually alluring; for example, as stated by Sommers-Flanagan and Davis (1993), "like lip licking, stroking one's body, and pelvic thrusting” (p. 746). Black male rapper 
video presents the "ideal" masculine lifestyle-that one must have certain brands, big mansions, nice cars, expensive drinks, and jewelry; and if the video cannot fulfill the 'dream' of its audience, then the rapper is considered unattractive.

There are a few examples of some male hiphop rappers who frequently use Black women's bodies in their songs, either from the lyrics or videos. The first example is a song entitled Baby Got Back (1991), sung by the controversial Sir Mix-a-Lot who raps, "I like big butts and I cannot lie" (line 9). The song celebrates black women's voluptuous butts as symbols of desirability,

I like 'em round, and big I just can't help myself

I'm actin' like an animal

Now here's my scandal

I wanna get you home

And ugh, double-up, ugh, ugh"

(Baby Got Back, 1991, line 42-47)

The lyrics above show that this song emphasizes the objectivity of Black women's bodies. In fact, its video shows the round posteriors of black women dancers and enormous sculptures of women's buttocks in the whole video. There are two Black women dancers who dance in a sexy way, while the camera focuses on their posteriors, while there are some men and women look at or admire the dancers' bodies. So it can be said that Baby Got Back is a form of male domination over women's bodies. Women's bodies are explored by the male gaze.

These Black women that are represented in the video are the development of the controlling image of the Jezebel in the slavery era, and the Jezebel image serves as the hypersexual construction of Black women. The image of the jezebel is known as the sexual object and not a subject of her own sexual desire. From Black Jezebel, it turns into The Gold Digger image that depicts a woman who is consciously aware that her sexuality can be used to gain economic rewards (Ross and Coleman, 2011, p. 160).

From here, according to the present writer, there are two ways to refuse the objectification of Black woman body. One is by making different beauty standard to counter negative images, just like Missy Elliot, or there is another example by India Arie with her song entitled Video,

I'm not the average girl from your video

And I ain't built like a supermodel But I learned to love myself unconditionally

Because I am a queen

I not the average girl from your video

My worth is not determined by the price of my clothes

(Video, line 5-10)

The lyrics above are a form of protest from India Arie about standards or labels that are given by society to Black women who have always been associated with hyperexuality.

While the second way is by reclaiming and revising the controlling images by expressing sexual subjectivity; that Black women's sexuality is positive and enjoyable, exemplified by Beyonce. She is consistently 
challenges notions of what it means to be a woman even since her first album, Dangerously in Love album that actually functions as her first step toward a "new liberated image" for her to claim of subjectivity by asserting her sexuality on her own terms. For example in her Baby Boy lyrics,

Baby boy, you stay on my mind Fulfill my fantasies I think about you all the time I see you in my dreams Baby boy, not a day goes by Without my fantasies

(Baby Boy, line 7-12)

Beyonce as a Black woman singer rejects the notion of women as merely sexual objects in hip-hop by expressing her own sexuality. In Baby Boy, Beyonce shows the Black woman's sexuality by discussing her fantasies and desires towards the male partner, rather than being submissively objectified. For another example in her song entitled Rocket,

Let me sit this ass on you

Show you how I feel

Let me take this off

Will you watch me?

That's mass appeal

Don't take your eyes off it

Watch it, babe

If you like you can touch it, baby

Do you, do you wanna touch it, baby?

(Rocket, line 1-10)

The lyrics above shows how a woman sees sexual activity, how a woman wants to be equal in getting pleasure. A woman does not mean to be passive and submissive to the male partner, in fact Beyonce as the singer shows that she gives an instruction to her male partner to get sexual pleasure. Mostly, though there are some women who are not passive, most of them will let their male partners initiate the 'action', but there are also women who have different tastes in getting pleasure, so that they are more frequently start and give instruction on the 'action'; as shown in the above lyrics.

Previously said that when a woman's body is explored by a man's gaze, it leads to objectivity. Now, when women begin to explore their own bodies, then it is called sexual subjectivity. As mentioned by Martin (1991) that, "sexual subjectivity is important for Black woman because affects her ability to act in the world, and to feel like she can do anything and make them happen." (p. 10). Women's sexual subjectivity contrasts the patriarchal objectification that sees or even commodifies women's sexuality for men's satisfaction.

The idea of women's sexual subjectivity appears in response to highly repressive discourses of sexuality, and as stated by Glick (2000) that this notion is related to "Sex Positivity movement" (p. 20). According to Fahs (2014), "the sex positivity movement happened around 1980s, 'where feminists battled about pornography in response to the pro-censorship notions from radical feminists"” (p. 272). In other words, Anti-pornography feminists saw pornography as a tool of patriarchy used to promote male dominance over women. However, not all feminists at this time felt the same way. Sex-positive feminists hold the view that there is nothing wrong with any 
sort of sexual activity between adults, and that sexual freedom is essential to women's liberation.

From those songs that talk about sexual pleasure, all of them have video clip but unfortunately do not explicitly depicts a sexual activity; even though from those three video clips, Beyonce is totally exploring and exposing her body. For example, Rocket with its very sensual lyrics, has a black and white themed video that stars Beyonce herself, without the male partner actor. Beyonce is shown as a woman who narrated her experience and imagination to achieve satisfaction. The video setting is a house, while Beyonce wears sexy clothes and moves sensually to every corner of the building such as the bedroom, bathroom, kitchen, and living room. It suggests that Beyonce as a Black woman has full power of her body and her imagination. In making a sensual imagination for her male partner, Black woman can make her own erotic scene and makes the male partner to follow it so both the Black woman and man get a pleasure.

Based on the entire explanation above, it can be said that sexuality is most often highlighted in hip-hop; especially if it is associated with a Black woman. Besides because sexuality is a very private thing, the influence of historical background and the intersection of class, race, and gender politics makes sexuality become an important issue to be discussed. Then, Black women artists that were mentioned above, especially Beyonce encourage Black women to embrace their sexuality and personal expression. Black women were not given the right to body autonomy or sexual freedom, and then by embracing their sexuality, Black women have power over their own bodies without any interference or particular standards made by other people or other groups.

\section{Conclusion}

Having analyzed Beyonce's songs in her latest album entitled Beyoncé Platinum Edition Album, it can be concluded that there are some concepts of womanhood shown by Beyonce. First of all, the importance of being oneself, the important to improve Black women solidarity to fight against patriarchy, the importance of the mother and daughter relationship, and subsequently, Beyonce's indication that a love relationship with a Black man can improve the quality of Blacks because to be a solid group within the society, Black women and Black men must be united.

For Blacks, Hip-Hop plays an important role for them, but in some cases, by embracing their sexuality, Black women have power on their own bodies without any intervention or particular standards by others. It is considered as objectifying Black woman's body, Beyonce tries to encourage Black women to embrace their sexuality and personal expression.

\section{References}

Collin, P. H. (1991) Black Feminist Thought: Knowledge, Consciousness, and the Politics of Empowerment. New York: Routledge. . (2006) From Black Power To Hip Hop. Philadelphia: Temple University Press. 
Conrad, K. D., Dixon, T. L. \& Zhang, Y. (2009). Controversial Rap Themes, Gender Portrayals And Skin Tone Distortion: A Content Analysis Of Rap Music Videos. Journal of Broadcasting \& Electronic Media, 53, 134-156.

Creswell, J. W. (2009) Research Design Qualitative, Quantitative, And Mixed Methods Approaches. London: Sage Publications Ltd.

Denzin. N. K., and Lincoln, Y. S (2005) The Discipline And Practice Of Qualitative Research: Handbook of Qualitative Research (3rd ed.). California: Sage Publisher.

Dickson. L. (1993). The Future Of Marriage And Family In Black America. Journal of Black studies, 23. 4. 472491.

Fahs, B. (2014) 'Freedom to' and 'freedom from': A new vision for sex-positive politics. Sexualities. Vol. 17(3) 267290.

Glick, E. (2000). Sex Positive: Feminism, Queer Theory, and the Politics of Transgression. Feminist Review, No. 64, Feminism 2000: One Step beyond?. Spring, pp. 19-45.

Greer, G. (1999) The whole woman. Transworld Publishers: London

Hooks, B. (1992) Black Looks: Race and Representation. Boston: South End Press

. (2000) Feminism is for Everybody: Passionate Politics. Cambridge: South End Press

Livingstone, R. M. (2012) Grief And High Conflict Divorce. Chicago: Adler Graduate School

"Lyrics". (1997). Encyclopedia Americana (Vol. 16,. 778). Danbury: Grolier, Inc..

Marshall, A. (1996) Reconstructing Womanhood, Reconstructing
Feminism: Writings on Black Women. London: Routledge.

Martin, B. L. (1991). From Negro to Black to African American: The Power of Names and Naming. Political Science Quarterly Vol 106, No. 1 (Spring). pp. 83-107. The Academy of Political Science.

Michie, H. (1992) Sororophobia: Differences among Women in Literature and Culture. New York: Oxford University Press,

Muhammad, S. (2011). Broken Black Relationship: where is the love? Web. http://newamericamedia.org/2011/09 /broken-black-relationships-whereis-the-love.php. Retrieved on June $3^{\text {rd }}, 2015,6: 39$

Norfleet, D. M. (2006) Hip-Hop and Rap. African American Music: An Introduction. In M. Burnim \& P. Maultsby. New York: Routledge.

Penington, B. (2004). The Communicative Management Of Connection And Autonomy In African-American And European-American MotherDaughter Relationships. The Journal of Family Communication, Vol. 4, no. 1, pp. 3-34.

Pinderhughes, E. (2002). African American Marriage in the $20^{\text {th }}$ Century. Family process, Vol. 41. No. 2. $269-282$.

Pluhar, E. I. \& Kuriloff, P. (2004) What really matters in family communication about sexuality? A qualitative analysis of affect and style among African American mothers and adolescent daughters. Journal of Sex Education, Vol. 4, no. 3, pp. 303-321.

Ross, Jasmine N. and Coleman, N. M. (2011). Gold Digger Or Video Girl: The Salience Of An Emerging HipHop Sexual Script. Culture, health, 
\& sexuality. Vol 13, no. 2, February, $157-171$.

Sewell, R. (2013). What is Appealing?: Sex And Racial Differences In Perceptions Of The Physical Attractiveness of Women. Undergraduate research journal. Vol. 6. No. 2. 56-70.Florida: The University Of Central Florida.

Sommers-Flanagan, R., \& Davis, B. (1993). What's Happening On Music Television? A Gender Role Content Analysis. Sex Roles, 28, 745-753.

Strauss, A. L. and Corbin, J. M. (1998). Basics of Qualitative Research: Technique and Procedures for developing grounded theory. California: Sage Publication, Inc..

Taylor, P. C. (1999). Malcolm's Conk and Danto's Colors; or Four Logical Petition Concerning Race, Beauty, and Aesthetics. The Journal of
Aesthetics and Art Criticism, VOl. 57, No. 1. Pp. 16-20.

Wanzo, R. (2011). Black love is not a fairy tale: African American women, romance, and rhetoric.

An interdisciplinary journal of rhetorical analysis and invention. No. 7. Vol. 2. 1-18.

Ward, R. R. \& Herndl, D. P. (1997) "Ethnicity." In Feminisms. An Anthology of literary theory and criticism. New Jersey: Rutgers University Press

Williams, C. I. (2015). Sisterhood in Action: What It Means for Black Women to Really Take Care of Each Other. Retrieved from http://www.forharriet.com/2015/04/si sterhood-in-action-what-it-meansfor.html\#ixzz3WRZwsTmr oApril, $4^{\text {th }} 2015,13: 40$ 